\title{
Immunogold Quantification of Glutamate in Two Types of Excitatory Synapse with Different Firing Patterns
}

\author{
Oleg Shupliakov, ${ }^{1,2}$ Lennart Brodin, ${ }^{1}$ Staffan Cullheim, ${ }^{2}$ Ole Petter Ottersen, ${ }^{3}$ and Jon Storm-Mathisen ${ }^{3}$ \\ 'The Nobel Institute for Neurophysiology and 2Department of Anatomy, Karolinska Institutet, S-104 01 Stockholm, Sweden \\ and ${ }^{3}$ Department of Anatomy, Institute of Basic Medical Sciences, University of Oslo, N-0317 Oslo, Norway
}

\begin{abstract}
A quantitative immunocytochemical method was used to study the regional levels of glutamate in two types of lamprey (Ichtyomyzon unicuspis) axon, which both activate excitatory amino acid receptors, but which when active exhibit different firing patterns. Giant reticulospinal axons fire in brief bursts, while dorsal column axons, mainly belonging to cutaneous afferents, show a sustained firing at high frequency. In both types of axon, clusters of synaptic vesicles showed a strong accumulation of glutamate immunogold labeling, and the density of gold particles correlated strictly with the packing density of synaptic vesicles. The most densely packed vesicle areas had a particle density corresponding to a concentration of fixed glutamate of about $30 \mathrm{mM}$ in coprocessed glutamate conjugates, suggesting an intravesicular glutamate concentration of at least $60 \mathrm{mM}$. The level of labeling in axoplasmic matrix was considerably lower, but differed significantly between the two types of axon. Dorsal column axons showed a particle density in axoplasmic matrix that was approximately four times higher than that in giant reticulospinal axons. The mitochondrial glutamate labeling was also significantly stronger in the dorsal column axons. In addition, the number of mitochondrial profiles surrounding vesicle clusters was about four times higher in dorsal column synapses than in reticulospinal synapses. Antisera to aspartate, GABA, glutamine, and homocysteate failed to produce a specific labeling of synaptic vesicle clusters in reticulospinal or dorsal column axons. In conjunction with previous demonstrations of a stimulus-induced vesicle depletion in giant reticulospinal synapses (Wickelgren et al., 1985), these results imply that glutamate is released from synaptic vesicles. The different extravesicular glutamate levels in reticulospinal axons and dorsal column axons may relate to different requirements for the refilling of synaptic vesicles in these functionally divergent neurons.
\end{abstract}

Glutamate appears to be the major excitatory transmitter in the $\mathrm{CNS}$, acting at a diversity of ionotropic and second messengercoupled receptors (Hollman et al., 1989; Monaghan et al., 1989;

\footnotetext{
Received Dec. 13, 1991; revised Mar. 31, 1992; accepted Apr. 17, 1992.

This work was supported by the Norwegian Council for Science and the Humanities, The Swedish Medical Research Council (Grant 10378 and 9284), The Swedish Socialstyrelsens fonder, and The European Science Foundation (travel fellowship). We thank Prof. A. Rustioni for the generous supply of aspartate antiserum, and Prof. S. Grillner for valuable comments on the manuscript.

Correspondence should be addressed to Lennart Brodin, The Nobel Institute for Neurophysiology, Karolinska Institutet, Box 60400, S-104 01 Stockholm, Sweden.

Copyright (C) 1992 Society for Neuroscience $0270-6474 / 92 / 123789-15 \$ 05.00 / 0$
}

Masu et al., 1991; Moriyoshi et al., 1991). In addition, glutamate plays a ubiquitous metabolic role, and it has therefore been difficult to detail the role of glutamate in synaptic function (Fonnum, 1984; Nicholls, 1989). The availability of antibodies to amino acids (Storm-Mathisen et al., 1983; Liu et al., 1989) and their use with the postembedding immunogold method (Somogyi and Hodgson, 1985; Ottersen, 1987, 1989) have markedly improved the possibilities to distinguish between different "pools" of glutamate, because glutamate immunoreactivity in different neuronal elements can be quantified and examined at high anatomical resolution. Most studies employing this method conclude that putative excitatory nerve terminals contain about two to five times higher levels of glutamate than other neuronal elements (see, e.g., Somogyi et al., 1986; Ottersen, 1987, 1989; Montero and Wenthold, 1989; Maxwell et al., 1990; Ottersen et al., 1990; Storm-Mathisen and Ottersen, 1990; Ji et al., 1991; Broman and Ottersen, 1992). However, due to the complex organization of the mammalian CNS, it has been difficult to apply this method to identified nerve terminals with known physiological properties (cf. insects, Watson, 1988). Furthermore, attempts to determine the local glutamate levels in different subcompartments of nerve terminals have been hampered by their complex structural features. Both of these problems can be overcome in the lamprey CNS, which contains certain large identifiable axons with en passant synapses, of which the pharmacology has been characterized using paired intracellular recording techniques (for review, see Brodin and Grillner, 1990). In this study, we have focused on two types of axon, which both activate excitatory amino acid (EAA) receptors on spinal neurons (Brodin et al., 1987, 1988b; Buchanan et al., 1987; Christenson and Grillner, 1992), but which differ markedly with regard to their function and pattern of activity. Giant reticulospinal axons (Müller cell axons), located in the ventromedial spinal cord, mediate rapid commands to the spinal motor circuitry, such as steering commands and vestibular responses (Rovainen, 1979; Brodin et al., 1988b; Kasicki et al., 1989; Grillner et al., 1991). These neurons are likely to be active only for brief periods in the living animal. When active, they exhibit a phasic pattern of activity with short bursts of action potentials, and within a burst the action potentials are spaced by long-lasting afterhyperpolarizations (Brodin et al., 1988a; Kasicki et al., 1989; Viana di Prisco et al., 1991). In contrast, pressure-sensitive cutaneous afferents (P-type intraspinal dorsal cells; Christenson et al., $1987 \mathrm{a}, \mathrm{b})$, with axons in the dorsal column, exhibit a tonic firing pattern. These cells have a very brief postspike afterhyperpolarization, and they fire continuously at high rate during ongoing skin stimulation (Christenson et al., 1987a,b). Although indi- 
vidual axons of P-type dorsal cells cannot be identified morphologically, they are known to constitute a large proportion of the excitatory axons in the dorsal column (see Results; Christenson et al., 1987a,b; Brodin and Grillner, 1990). In the present study, the postembedding immunogold technique was used to quantify the subcellular distribution of glutamate in giant reticulospinal and dorsal column synapses, and in addition, their general ultrastructural features were compared.

Two preliminary accounts of the present work have been published previously (Storm-Mathisen and Ottersen, 1990; Brodin et al., 1991)

\section{Materials and Methods}

Two adult lampreys (Ichtyomyzon unicuspis) were anesthetized by immersion in a solution of tricaine methane sulfonate (MS-222). The spinal cords were dissected and thereafter maintained in lamprey physiological solution at a pH of 7.4 (Kasicki et al., 1989) for at least $30 \mathrm{~min}$. Under this condition neither the giant reticulospinal axons nor the cutaneous afferent dorsal cells display any spontaneous action potentials, and therefore these elements can be considered to have been fixed after a period of rest. The spinal cords were fixed for $4 \mathrm{hr}$ in $3 \%$ glutaraldehyde (one animal, experiments 1,2 , and 4 ) or in $2.5 \%$ glutaraldehyde and $1 \%$ paraformaldehyde (one animal, experiment 3 ), both in $0.1 \mathrm{M}$ phosphate buffer ( $\mathrm{pH} 7.4)$. After washing in phosphate buffer $(4 \mathrm{hr})$, they were postfixed for $1 \mathrm{hr}$ in $1 \%$ osmium tetroxide in the same buffer and then dehydrated in alcohol and embedded in Epon-812 or Durcupan ACM (Fluka).

Serial ultrathin sections were collected on nickel grids. The immunogold procedure was based on that of Somogyi and Hodgson (1985) and has been described in detail previously (Ottersen, 1987, 1989). Following treatment with $1 \% \mathrm{HIO}_{4}(7 \mathrm{~min})$ and $9 \% \mathrm{NaIO}_{4}(15 \mathrm{~min})$, the sections were preincubated in $1 \%$ human serum albumin in Trisphosphate-buffered saline (TPBS; $20 \mathrm{~min}$ ) and then incubated for $2 \mathrm{hr}$ in antiserum diluted with TPBS with the appropriate amino acid-glutaraldehyde $(\mathrm{G})$ complexes added in order to remove cross-reactivities (Ji et al., 1991). The following combinations were used: anti-glutamate 03 absorbed with Sepharose-BSA-G-GABA (Ji et al., 1991) 1:600, with aspartate-G $(300 \mu \mathrm{M})$ and glutamine-G $(100 \mu \mathrm{M})$; anti-glutamine 34 absorbed with Sepharose-BSA-G-glutamate and mycobacteria from the adjuvant (Laake et al., 1986; Zhang et al., 1991) 1:500, with aspartatc$\mathrm{G}(100 \mu \mathrm{M})$; anti-aspartate 18 absorbed with Sepharose-BSA-G-GABA (Ottersen and Storm-Mathisen, 1985; Zhang et al., 1990) 1:200, with glutamate-G $(30 \mu \mathrm{M})$ and taurine-G $(30 \mu \mathrm{M})$; anti-aspartate (Hepler et al., 1988) 1:2000; anti-homocysteate (Zhang and Ottersen, in press) 1:200, with $200 \mu \mathrm{M}$ glutamate-G; anti-GABA AB 131 (Chemicon Inc.) $1: 3000$. After a brief rinse in polyethylene glycol $(50 \mathrm{mg} / 100 \mathrm{ml}$ in Tris $\mathrm{HCl}$ buffer, $\mathrm{pH}$ 7.4), the sections were incubated with goat anti-rabbit IgG coupled to colloidal gold particles (diameter, $15 \mathrm{~nm}$; Amersham), diluted 1:20 in the same polyethylene glycol solution. The sections were stained with uranyl acetate and lead citrate and examined in a Philips 301 or CM10 electron microscope. As a routine specificity control, the tissue sections were in all experiments incubated together with test sections (Fig. 1) containing fixation complexes of six different amino acids (Ottersen, 1987, 1989). In order to estimate the relationship between gold particle density and antigen concentration, the tissue sections were in one experiment coprocessed with sections from a laminated series of $\mathrm{OsO}_{4}$-treated conjugates, containing different concentrations of glutamate. The conjugates were prepared as described by Ottersen (1989), but with a different range of glutamate concentrations. The densities of gold particles over the graded conjugate series were then compared with that over different regions (for definition see below) of the tissue sections. It must be noted that the relationship between gold particle density and antigen concentration differs somewhat among different experiments (cf. Storm-Mathisen and Ottersen, 1990, with Ottersen et al., 1992), probably because it is sensitive even to small variations in the incubation parameters. The curve obtained (see Fig. 5) is thus valid only for the accompanying tissue sections (Table 1, experiment 3).

Electron micrographs at a final magnification of $47,250 \times$ were analyzed on a digitizing tablet coupled to a computer. The gold particles over different tissue profiles and subcellular compartments were counted and the particle densities were determined using the MORFOREL pro- gram (Blackstad et al., 1990). Statistical evaluation of the data was carried out by means of a commercial statistical package (SPSS/PC + ). The tissue profiles in which gold particle densities were calculated were defined as follows: (1) synaptic vesicle clusters: grouped vesicles attached to a synaptic specialization visible in the same or in an adjacent section, not including areas with single scattered vesicles; (2) axoplasmic matrix surrounding vesicles: the adjacent region within a radius of $360 \mathrm{~nm}$ from the border of a vesicle cluster; (3) axoplasmic matrix: areas of organelle-free axoplasm excluding areas within a radius of $360 \mathrm{~nm}$ from the border of a vesicle cluster; (4) presynaptic mitochondria: mitochondria'located in the axoplasmic matrix within a distance of $1 \mu \mathrm{m}$ from a synaptic vesicle cluster; (5) postsynaptic dendrites: dendritic profiles connected synaptically with dorsal column or giant reticulospinal axons; (6) glial processes: profiles containing filaments with a dimension and organization typical of glial cells. Each tissue section (Fig. 2) contained a region of tissue-free plastic in which the background level of gold particles could be determined. This level was below 5 particles $/ \mu \mathrm{m}^{2}$ in all experiments. The background level was subtracted from the average gold particle densities calculated for each cell compartment.

\section{Results}

General characteristics of synapses in giant reticulospinal axons and dorsal column axons

The spinal cord of adult Ichtyomyzon unicuspis is flattened and ribbon-like with a dorsoventral thickness not exceeding $250 \mu \mathrm{m}$. This makes it possible to study both dorsal column axons and the ventrally located giant reticulospinal axons (Fig. 2) in the same transverse ultrathin section. The reticulospinal axons belonging to giant Müller cells (Rovainen, 1979) can reach up to more than $40 \mu \mathrm{m}$ in diameter, and they are easily identified in transverse sections. These axons establish asymmetric en passant synapses on dendrites of spinal interneurons and motoneurons (Rovainen, 1979; Brodin et al., 1988b). The synapses contain spherical synaptic vesicles (Smith et al., 1968), and in some cases also gap junctions (Rovainen, 1974, 1979). Measurements of 200 synaptic vesicles from seven reticulospinal synapses gave an average vesicle diameter of $50 \pm 3 \mathrm{~nm}$ (mean \pm SEM). Axons of putative P-type cutaneous afferent dorsal cells are not as readily identified, but as they constitute a major proportion of the excitatory axons in the dorsal column, and belong to the large-diameter axons in this region (Christenson et al., 1987a,b; Brodin and Grillner, 1990), a reasonably homogeneous sample can be obtained. The following criteria were used: (1) only dorsal column axons with a diameter of 2-7 $\mu \mathrm{m}$ were included, (2) they all contained asymmetrical synapses with spherical synaptic vesicles of $50 \mathrm{~nm}$ diameter aggregated near the active zone, and (3) as judged from scrial scctions they wcre all devoid of electron-dense granules (see also below). For simplicity, the axons selected by these criteria will be referred to as "dorsal column axons." It should be noted, however, that a few axons of different type may have been included in this group. A fraction of the excitatory dorsal column axons belong to touchsensitive dorsal cells, which constitute about $15 \%$ of all dorsal cells (Christenson et al., 1987a,b), and a small number of axons originating from neurons located in dorsal root ganglia may also have been included (Brodin and Grillner, 1990). The physiological properties of the latter neurons have not been characterized. Three additional types of dorsal column axons were readily distinguished by their morphological characteristics. One type, showing intense GABA immunolabeling, contained spherical to pleomorphic vesicles, numerous dense bodies, and some dense-core vesicles (see Results and Fig. 8; J. Christenson and O. Shupliakov O, unpublished observations). A second type, presumably aminergic/peptidergic (see Brodin et al., 1988a), 


\section{A}
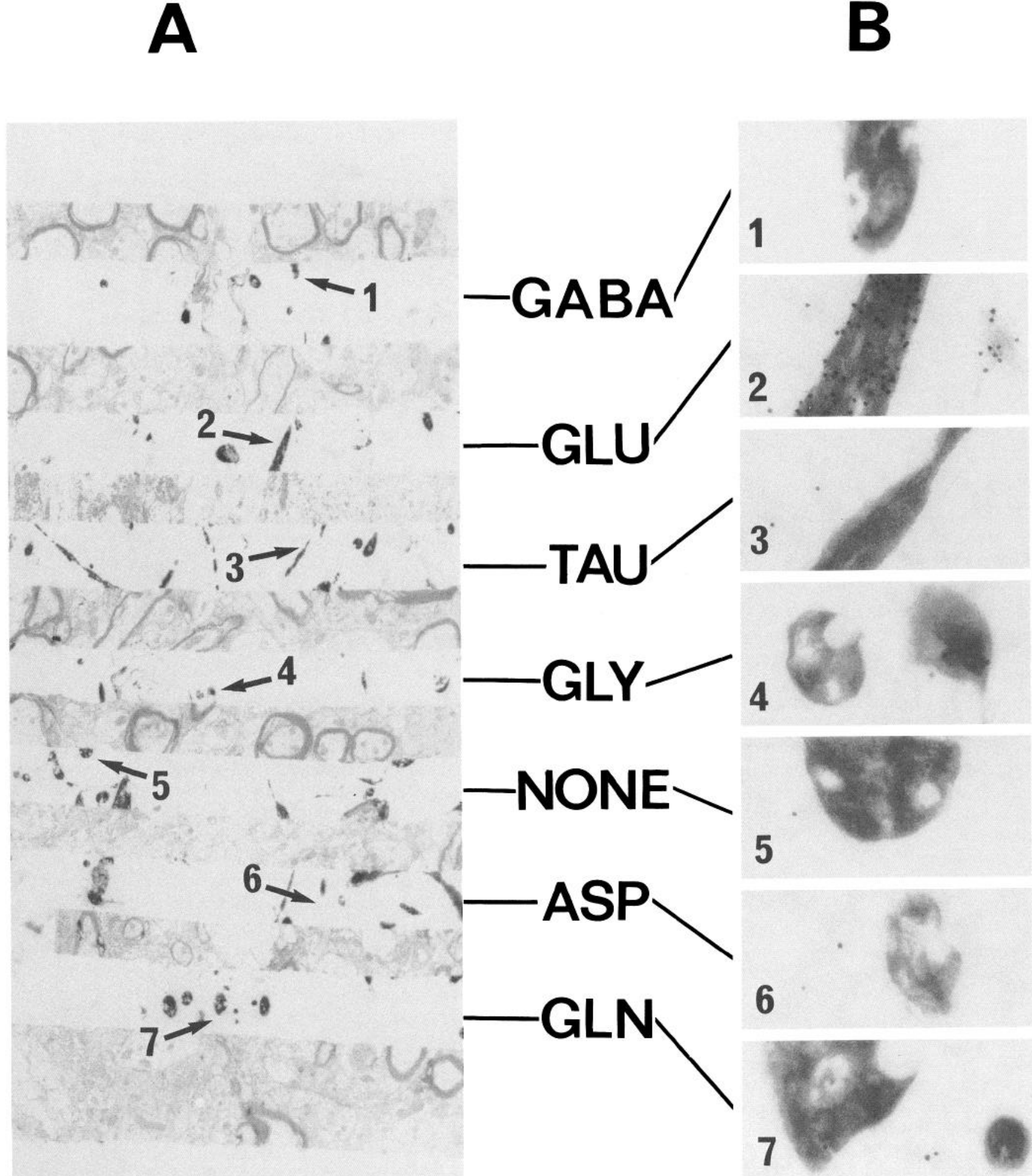

Figure 1. Specificity control of glutamate immunolabeling. $A$, Electron micrograph of a test section, containing glutaraldehyde-brain macromolecule conjugates of six amino acids: GABA, glutamate, taurine, glycine, aspartate, and glutamine. NONE represents conjugates made by reacting a macromolecule brain extract with fixative without addition of amino acids (for details, see Ottersen, 1987). The test conjugates shown were incubated together with the section in Fig. 3. B, Areas of the test section indicated on $A$ at high magnification. Note the selective accumulation of $15 \mathrm{~nm}$ gold particles over the glutamate-containing conjugates. 


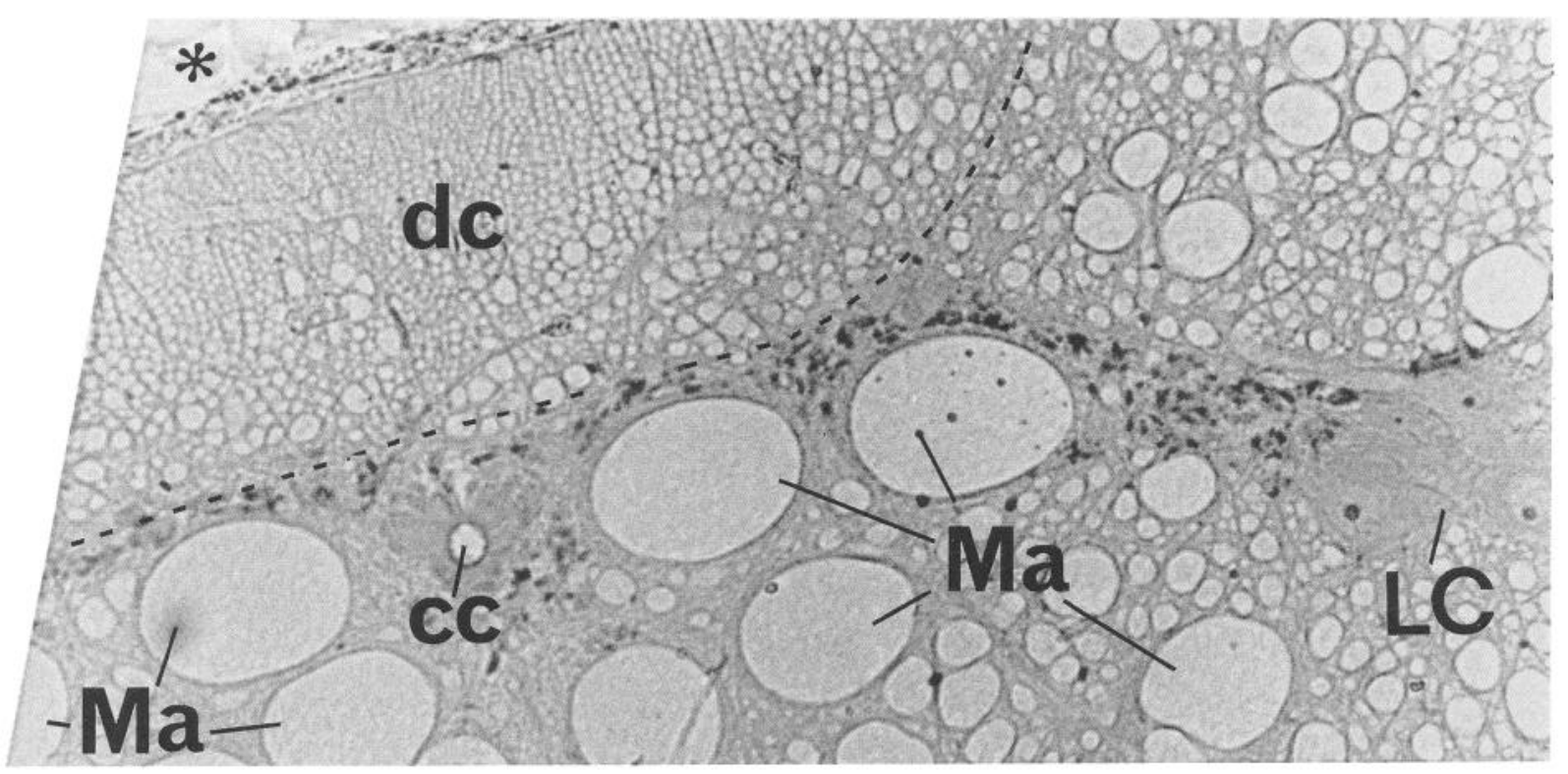

Figure 2. Light micrograph of a semithin section of one of the specimen from which ultrathin sections were taken. Ma, reticulospinal axons (Müller axons); $d c$, dorsal column; $c c$, central canal; $L C$, lateral cell column. The asterisk indicates the area of empty resin, used to estimate the background labeling (see Materials and Methods). Scale bar, $50 \mu \mathrm{m}$.

contained numerous large dense-core vesicles. A third type contained small flattened vesicles (not illustrated).

Although the giant reticulospinal synapses and the presumed excitatory dorsal column synapses were similar with regard to the postsynaptic density and synaptic vesicle morphology, they differed markedly in their content of presynaptic mitochondria (compare $A$ and $B$, Figs. 3, 6-9). In order to quantify this difference, the number of mitochondrial profiles within a radius of $1 \mu \mathrm{m}$ from the border of the vesicle cluster was counted in 52 randomly selected micrographs of each synapse type. The number of mitochondrial profiles differed by a factor of 4 between the two, with $1.1 \pm 0.4$ and $4.3 \pm 1.2$ for reticulospinal and dorsal column axons, respectively. Although the cross-sectional area of mitochondria was not compared, our preliminary analyses of serial sections have not revealed any difference in the size of mitochondria between the two types of synapse.

\section{General distribution of glutamate immunoreactivity}

Both giant reticulospinal and dorsal column synapses showed an accumulation of glutamate immunolabeling (Fig. 3). The labeling was concentrated over vesicle clusters and presynaptic mitochondria, whereas postsynaptic dendrites and axoplasmic matrix showed a comparatively weak staining. Glial cell bodies and processes were also weakly labeled. The intense aggregation of labeling over vesicle clusters and mitochondria could be traced in serial sections of one and the same synapse, and it was observed in all cases examined. The two different fixatives tested (see Materials and Methods) both produced a labeling of similar distribution and intensity.

\section{Quantitative determination of glutamate immunoreactivity}

Quantitative analysis showed that the density of gold particles over clusters of synaptic vesicles varied among individual synapses of each type. This variation was found mainly to be due to a different packing density of synaptic vesicles. A comparison of the gold particle density and the density of vesicles revealed a strong correlation between these parameters. The correlations for giant reticulospinal and dorsal column axons are shown in Figure $4, A$ and $B$, respectively.

Comparison of the glutamate immunolabeling in axoplasmic matrix in the two types of axon revealed that the particle density was 3-5 times higher (mean, 3.6; 3 experiments, experiment 4 not included; see Table 1) in dorsal column axons than in reticulospinal axons $(p<0.01$, multiple-range test, Student Newman-Keuls procedure). Consequently, the ratio of labeling between vesicle clusters and axoplasmic matrix differed markedly in the two synapse types, ranging between 11 and 23 (mean, $16.2 ; 3$ experiments) for the giant reticulospinal synapses and between 5 and 7 (mean, 6.0; 3 experiments) for dorsal column axons. The ratio of labeling between vesicle clusters and postsynaptic dendrites ranged between 7 and 9 (mean, 7.5; 3 experiments) for reticulospinal axons and between 5 and 12 (mean, $8.3 ; 3$ experiments) for dorsal column axons. In both types of axon the particle density in the matrix area adjacent to synaptic

Figure 3. Glutamate-like immunoreactivity in synapses established by reticulospinal $(A)$ and dorsal column $(B)$ axons located on the same ultrathin section of the lamprey spinal cord (see Fig. 1). The area containing synaptic vesicles $(s v)$ displays a high density of gold particles compared to axoplasmic matrix $(a x)$, dendrites $(d)$, and glial elements $(g)$. The density of gold particles is also relatively high over mitochondria $(m)$. Note the different labeling intensities of axoplasmic matrix and mitochondria in $A$ and $B$. The open arrow in $A$ indicates one $15 \mathrm{~nm}$ gold particle. Scale bar, $0.5 \mu \mathrm{m}$. 

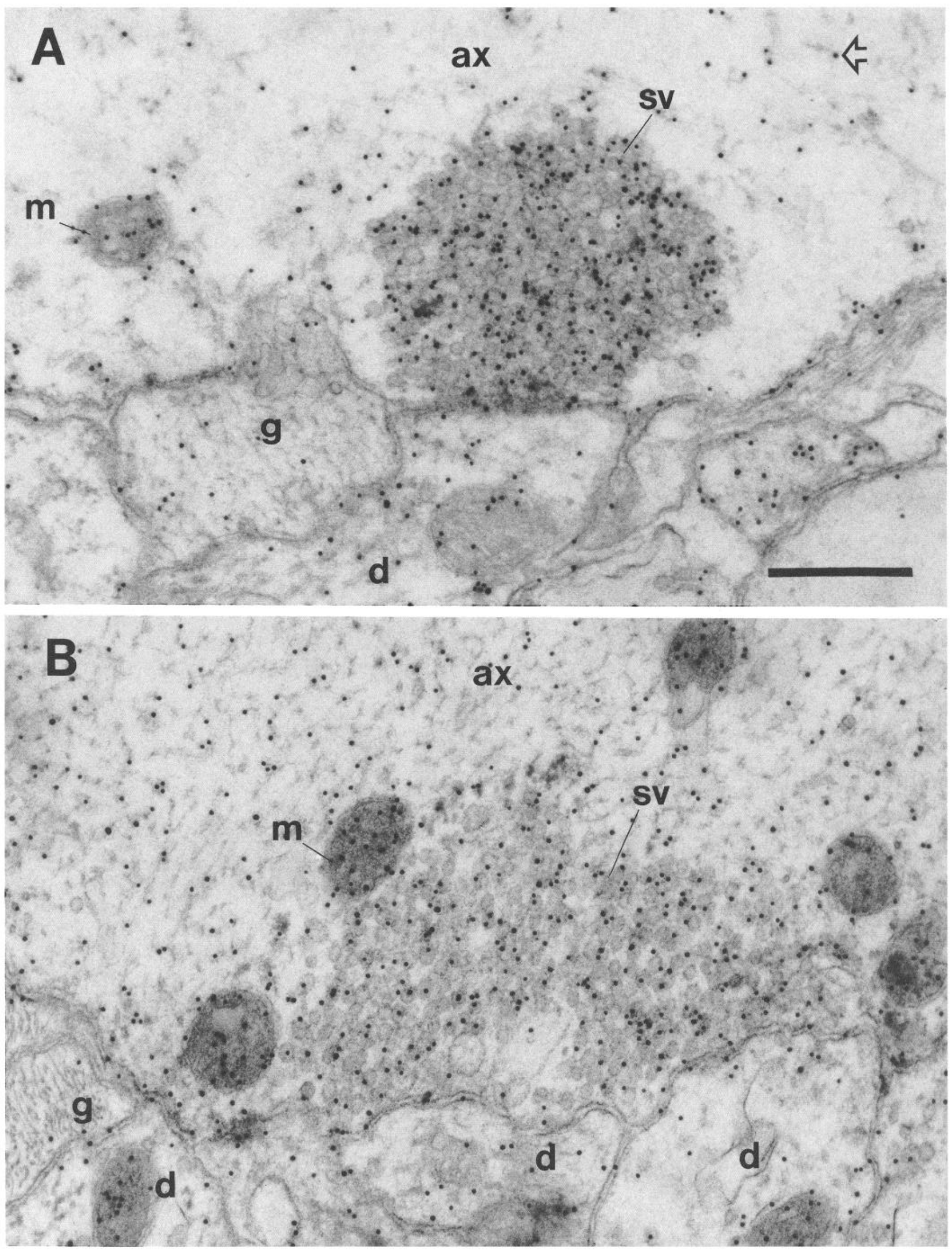
A

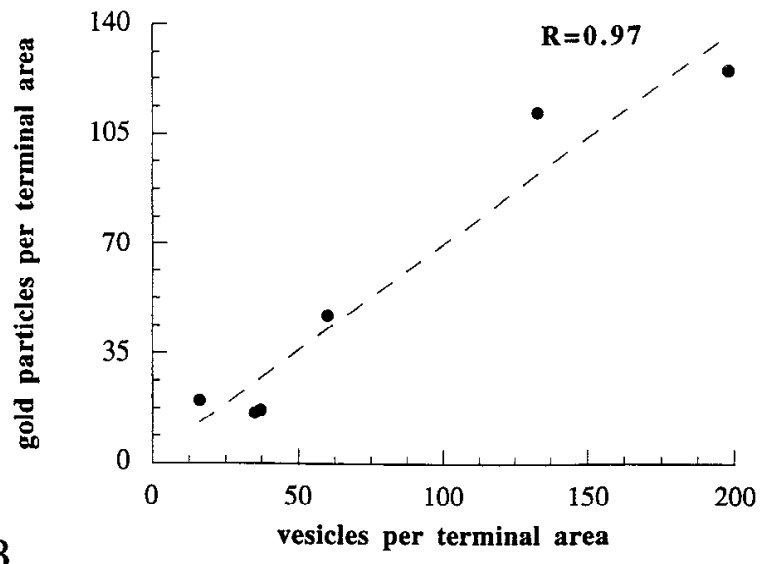

B

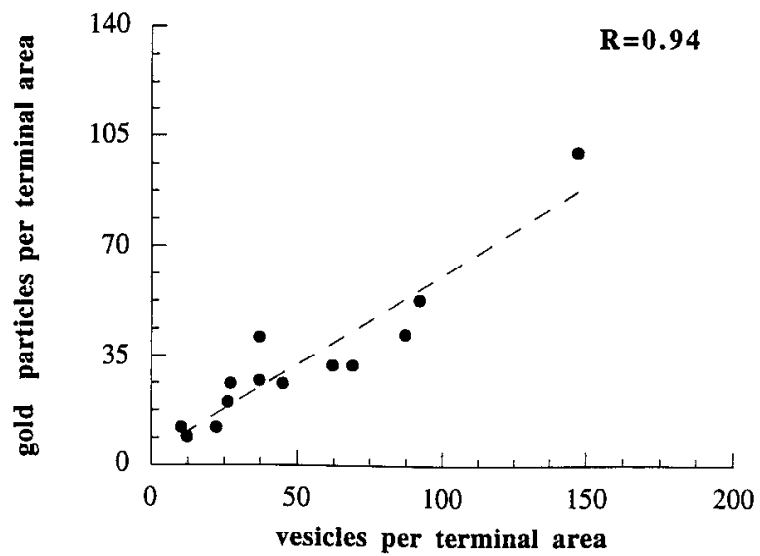

Figure 4. Correlation between the number of synaptic vesicles and the number of gold particles over vesicle clusters, in reticulospinal axons $(A)$ and dorsal column axons $(B)$ stained with glutamate antiserum. The data were obtained in experiment 3 . $R$, coefficient of correlation.

vesicle clusters (within $360 \mathrm{~nm}$ ) did not differ significantly from that in distant axoplasmic matrix (Table $1 ; p>0.05$ ).

The labeling intensity of presynaptic mitochondria, located within $1 \mu \mathrm{m}$ from vesicle clusters, also differed significantly between the two synapse types. It was 2-6 times higher (mean, $3.9 ; n=3$ ) in dorsal column axons than in giant reticulospinal axons, similar to the ratio for the axon matrix labeling.

In order to estimate the approximate concentrations of fixed glutamate in different elements, test sections containing a series of osmium-treated glutamate conjugates were incubated along
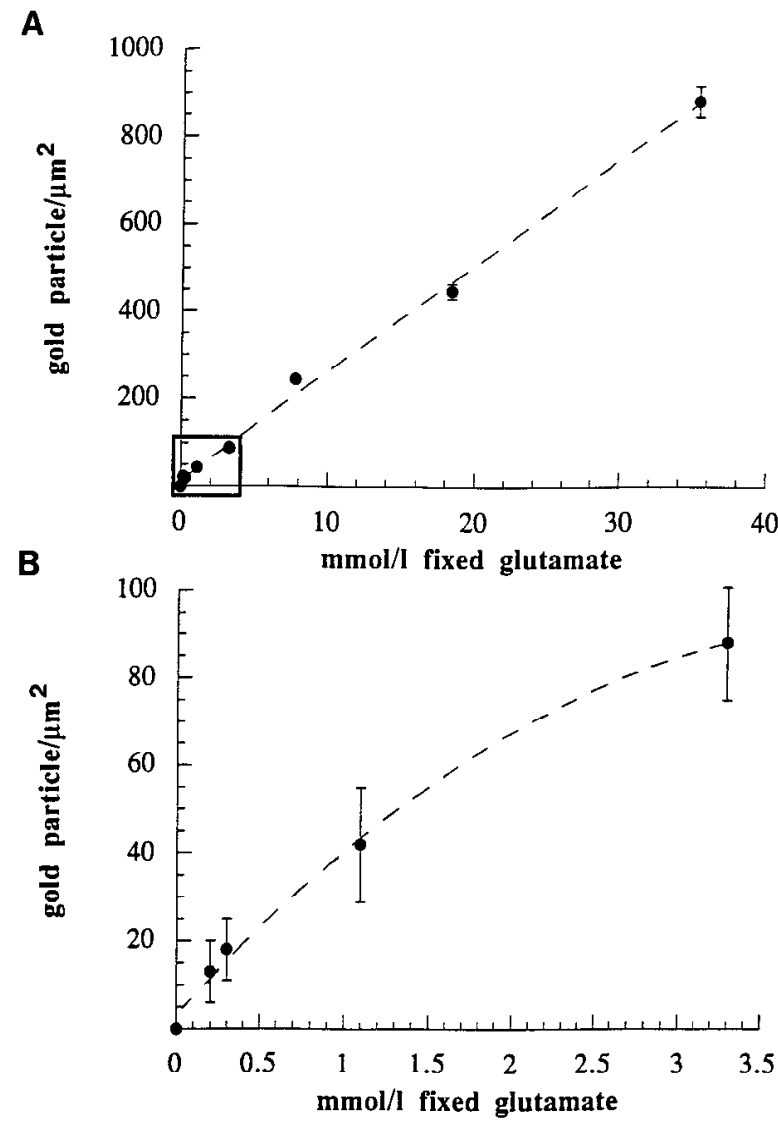

Figure 5. Relationship between the concentration of fixed glutamate and the gold particle density in glutamate-containing conjugates. The conjugates with different glutamate concentrations (calculated by use of radiolabeled glutamate) were treated with osmium before incorporation into the test sandwich. The test sections were incubated along with the tissue sections in experiment 3 . The values were corrected for background labeling over empty resin. The framed area in $A$ is shown with higher resolution in $B$. Error bars represent SEM.

with tissue sections (Ottersen, 1989; Storm-Mathisen and Ottersen, 1990). The relationship between the gold particle density and the glutamate concentration in the test conjugates is shown in Figure 5. The approximate concentration of fixed glutamate in the different neural elements can be inferred from the particle density values of cxpcriment 3 (Table 1). However, as the density of gold particles over vesicle clusters varied as a result of differences in the packing density of synaptic vesicles, an average

Table 1. Mean gold particle densities in dorsal column and reticulospinal axons, and surrounding elements

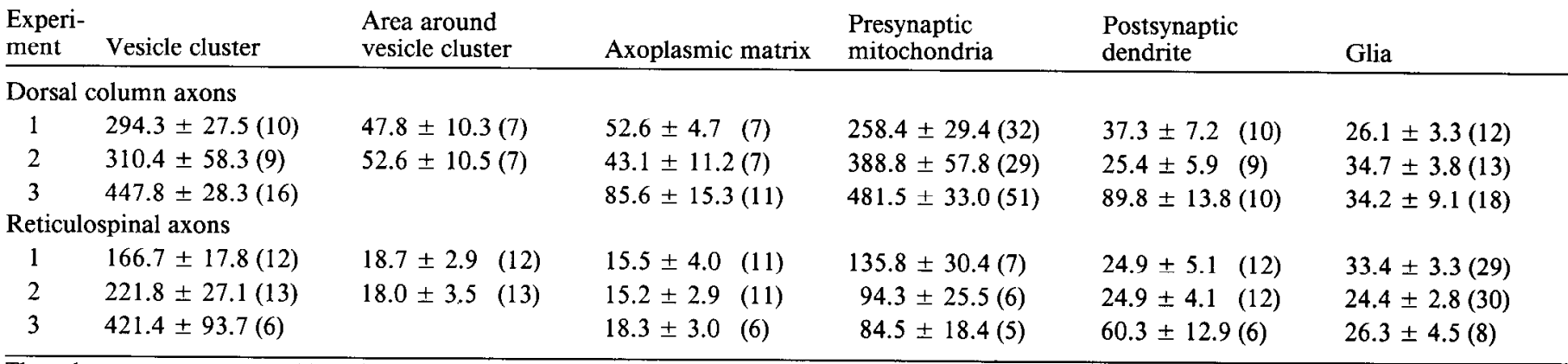

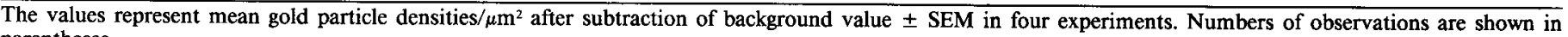
parentheses. 
value of this compartment will not be representative. In order to obtain a better estimate of the glutamate concentration in synaptic vesicle clusters, the gold particle density was quantified in selected vesicle areas where a high packing density of synaptic vesicles was observed. In these cases, similar values were obtained for both types of axons, ranging between 680 and 750 particles $/ \mu \mathrm{m}^{2}$, corresponding to an approximate concentration of fixed glutamate of 28-32 mM (Fig. 5). The intravesicular glutamate concentration can be expected to be even higher, since the axoplasmic matrix remaining between the packed vesicles and the vesicle membranes themselves contain little glutamate (see Discussion).

\section{Comparisons with aspartate, glutamine, GABA, and homocysteate immunoreactivity}

The two different aspartate antisera produced a very weak labeling of vesicle clusters, although the test sections incubated in the same drop of antiserum showed an intense labeling of the aspartate conjugate (Fig. 6). The axoplasmic matrix showed a very low level of labeling in giant reticulospinal axons, whereas in dorsal column axons it was somewhat higher and more variable between different axons. In both synapse types, a moderate enrichment of gold particles was present over mitochondria in pre-as well as postsynaptic profiles (Fig. 6). Neuronal cell bodies located in the lateral cell column displayed a relatively high level of aspartate labeling (not illustrated).

The antiserum raised against glutamine produced a moderate labeling of reticulospinal (Fig. 7A) and dorsal column axons (Fig. $7 B$ ). A similar density of gold particles was observed over organelle-free axoplasmic matrix and vesicle clusters, whereas presynaptic mitochondria showed an enhanced level of labeling. The particle density in axoplasmic matrix of the two types of synapse was quantified $(n=14)$, but in contrast with glutamate, no statistically significant difference was revealed $(10.1 \pm 2.2$ and $10.7 \pm 2.9$ gold particles $/ \mu \mathrm{M}^{\prime}$ in reticulospinal and dorsal column axons, respectively). Glial cell bodies and processes showed a strong accumulation of glutamine immunoreactivity (Fig. 7).

After incubation with the GABA antiserum (Fig. 8), the labeling over vesicle clusters and axoplasmic matrix in both axon types corresponded to that over empty resin (i.e., background level). A faint labeling occurred over pre- and postsynaptic mitochondria and in glial elements. A strong GABA labeling was present in terminals of different type, which contained spherical to pleomorphic vesicles with electron-dense granules and scant dense-core vesicles (Fig. 8B).

Antiserum to homocysteate produced a generally low level of labeling in both types of axon (Fig. $9 A, B$ ). A faint concentration of gold particles was observed over synaptic vesicle clusters, but the particle density never exceeded two times the value for axoplasmic matrix or postsynaptic dendrites. Unlike the aspartate, glutamine, and GABA antisera, the homocysteate antiserum gave rise to some labeling of the coprocessed glutamate- containing test conjugate in these experiments. A comparison of the labeling intensity of the glutamate conjugate, which contains approximately $150 \mathrm{mM}$ glutamate, with that of reticulospinal vesicle clusters, showed that the latter exhibited about one-third of the gold particle density seen in the glutamate conjugate. Thus, the weak homocysteate-like immunoreactivity can most likely be explained by slight cross-reactivity with glutamate (see Discussion; cf. also Zhang and Ottersen, 1992).

\section{Discussion}

Validity of the immunogold method for determining the concentrations of fixed glutamate in nervous tissue

Previous studies have shown that the density of immunogold labeling can be used for a rough quantitative determination of the concentration of fixed amino acids in ultrathin sections, with a lateral resolution of about $25 \mathrm{~nm}$ (Ottersen, 1989; Ottersen et al., 1992). It should be emphasized, however, that quantitative results obtained with the immunogold method should always be interpreted with caution, as the labeling intensity can be influenced by several factors. These include steric hindrance (see below), effects of osmium treatment, and the availability of proteins with lysine residues in different tissue compartments (see also discussion in Ottersen, 1989). At present, osmiumtreated glutamate conjugates were used for the concentration estimates, in order to compensate for the masking effect of osmium (Ottersen et al., 1992). Variability in the labeling efficiency caused by structural and biochemical differences between different neuronal elements is, however, difficult to determine. One possibility to be considered is that the protein-rich synaptic vesicle membranes (Südhoff and Jahn, 1991; Trimble et al., 1991) would favor the retention of amino acids during fixation. It seems unlikely, however, that this factor could explain the intense glutamate labeling of synaptic vesicle clusters, since antisera to aspartate, glutamine, and GABA failed to produce an accumulation of labeling over vesicles in these axons. Conversely, nerve terminals of other type, some of which can be labeled with GABA antiserum, do not show a similar accumulation of glutamate labeling over vesicles $(\mathrm{O}$. Shupliakov and L. Brodin, unpublished observations; cf. also Watson, 1988).

As judged from our micrographs, the content of neurofilaments in the axon matrix appears to be higher in dorsal column axons compared to giant reticulospinal axons (compare $A$ and $B$, Figs. 3, 6-9; see also Smith et al., 1968). It is therefore possible that the composition of the dorsal column axon matrix would favor the retention of glutamate during fixation, which would result in an artifactual difference between the two types of axon. However, we found no significant difference of the glutamine labeling in axon matrix between the two types of synapse. Furthermore, the difference in the mitochondrial glutamate labeling between the two types of axon suggests that larger amounts of glutamate are in fact synthesized in the dorsal column axons.

Another factor to consider is a possible redistribution of ami-

Figure 6. Electron micrographs of reticulospinal $(A)$ and dorsal column $(B)$ axons stained with aspartate antiserum. The open arrow in $A$ indicates one $15 \mathrm{~nm}$ gold particle. Note the lack of labeling of synaptic vesicle clusters. Axoplasmic matrix of the dorsal column axon profile also contains morc gold particles than in the case of reticulospinal axon. An aspartate-containing conjugate within a test sandwich, incubated along with the tissue section, is shown in $C$. Abbreviations are as in Figure 3. The aspartate antiserum described by Hepler et al. (1988) was used. Scale bar: 0.5 $\mu \mathrm{m}$ for $A$ and $B ; 0.65 \mu \mathrm{m}$ for $C$.

Figure 7. Electron micrographs of reticulospinal $(A)$ and dorsal column $(C)$ synapses stained with glutamine antiserum. The open arrow in $A$ indicates one gold particle. Note the strong labeling of glial elements and the moderate labeling of postsynaptic dendrites. Abbreviations are as in Figure 3. The inset $(B)$ shows labeling of the glutamine-containing conjugate in the test section. Scale bar: $0.5 \mu \mathrm{m}$ for $A$ and $C$; $0.65 \mu \mathrm{m}$ for $B$. 


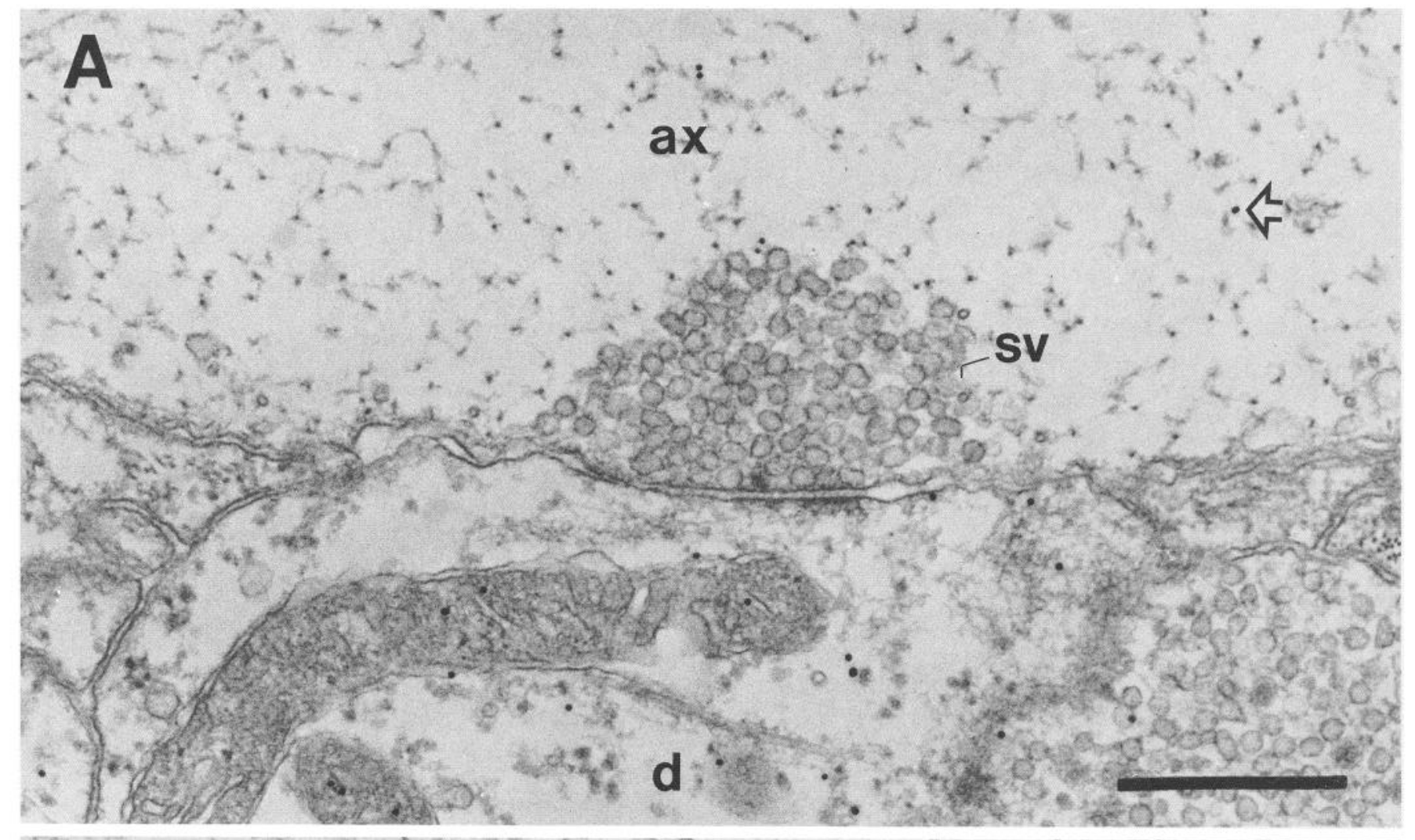

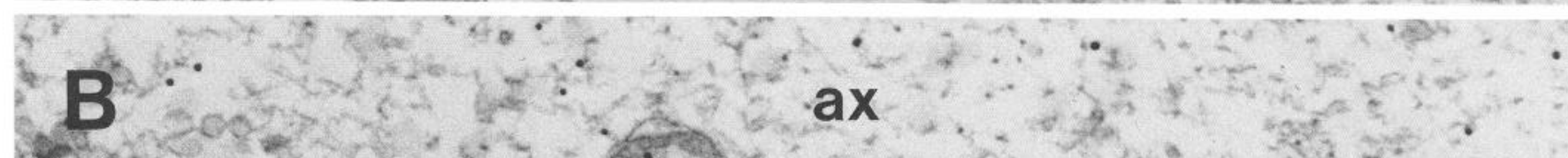
5)

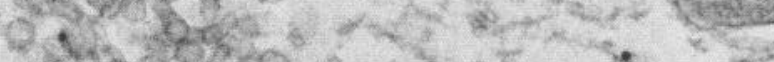

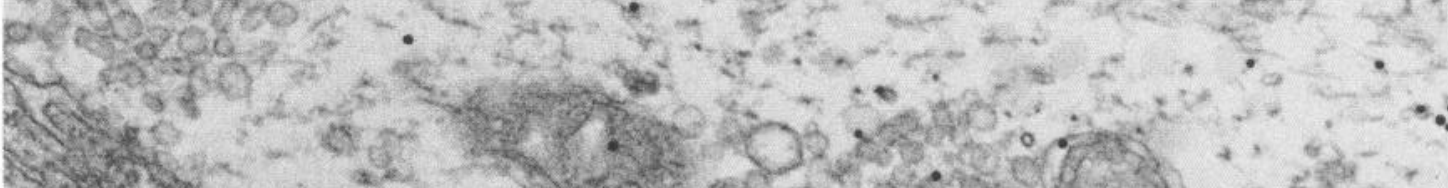

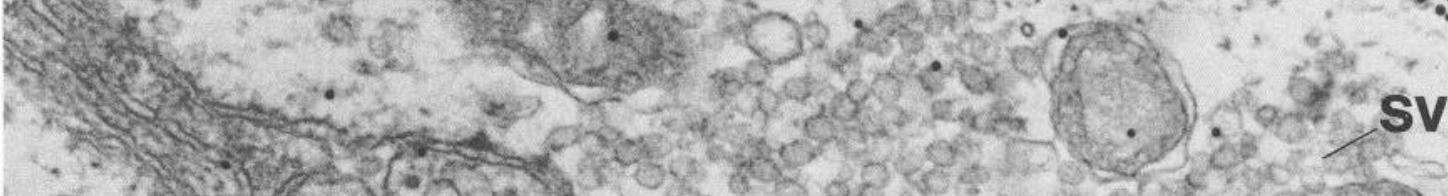
4.

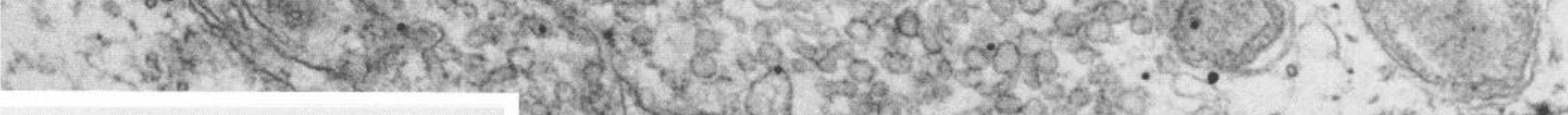

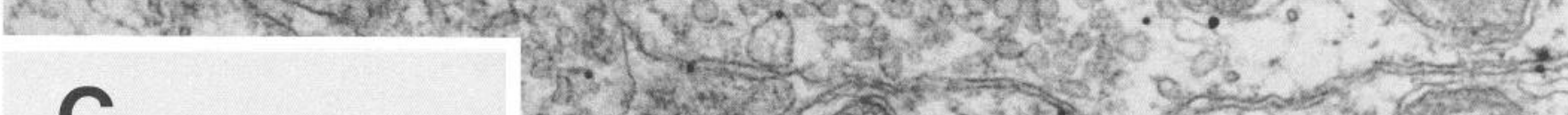

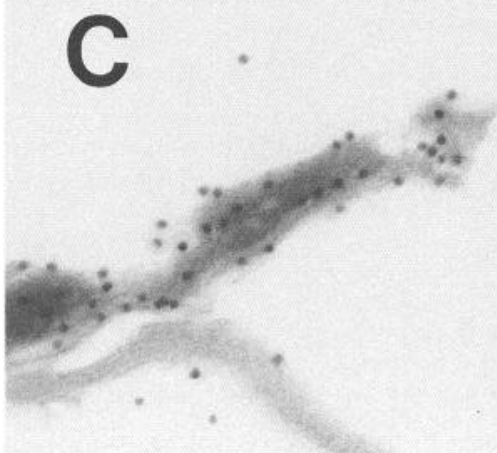

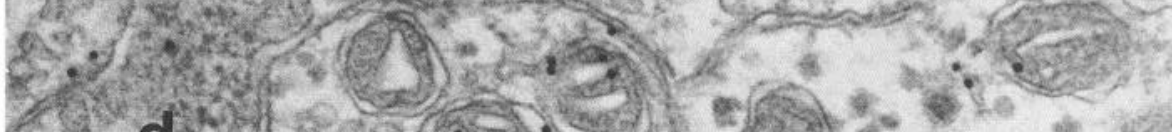

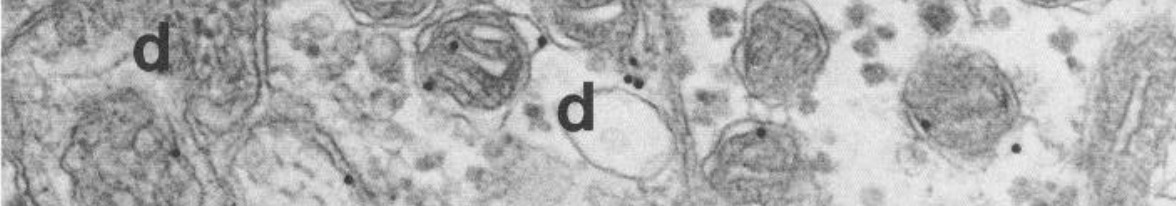

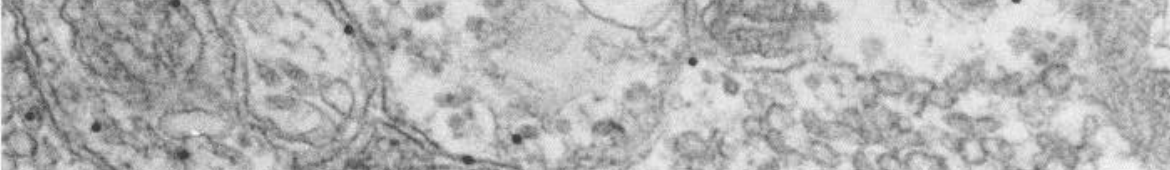

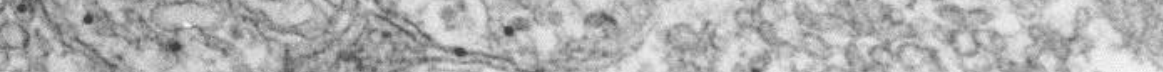

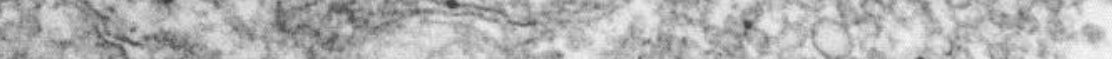




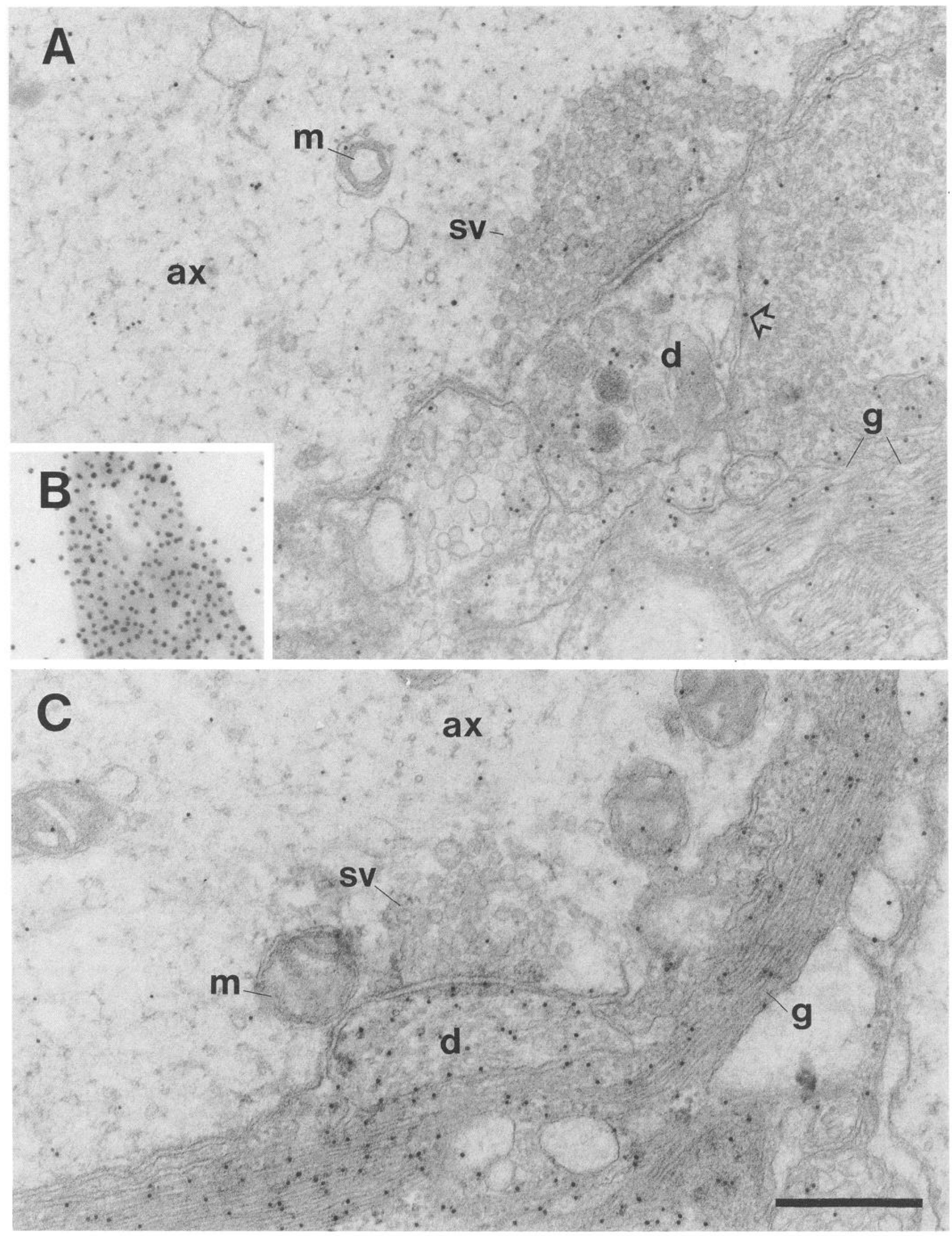



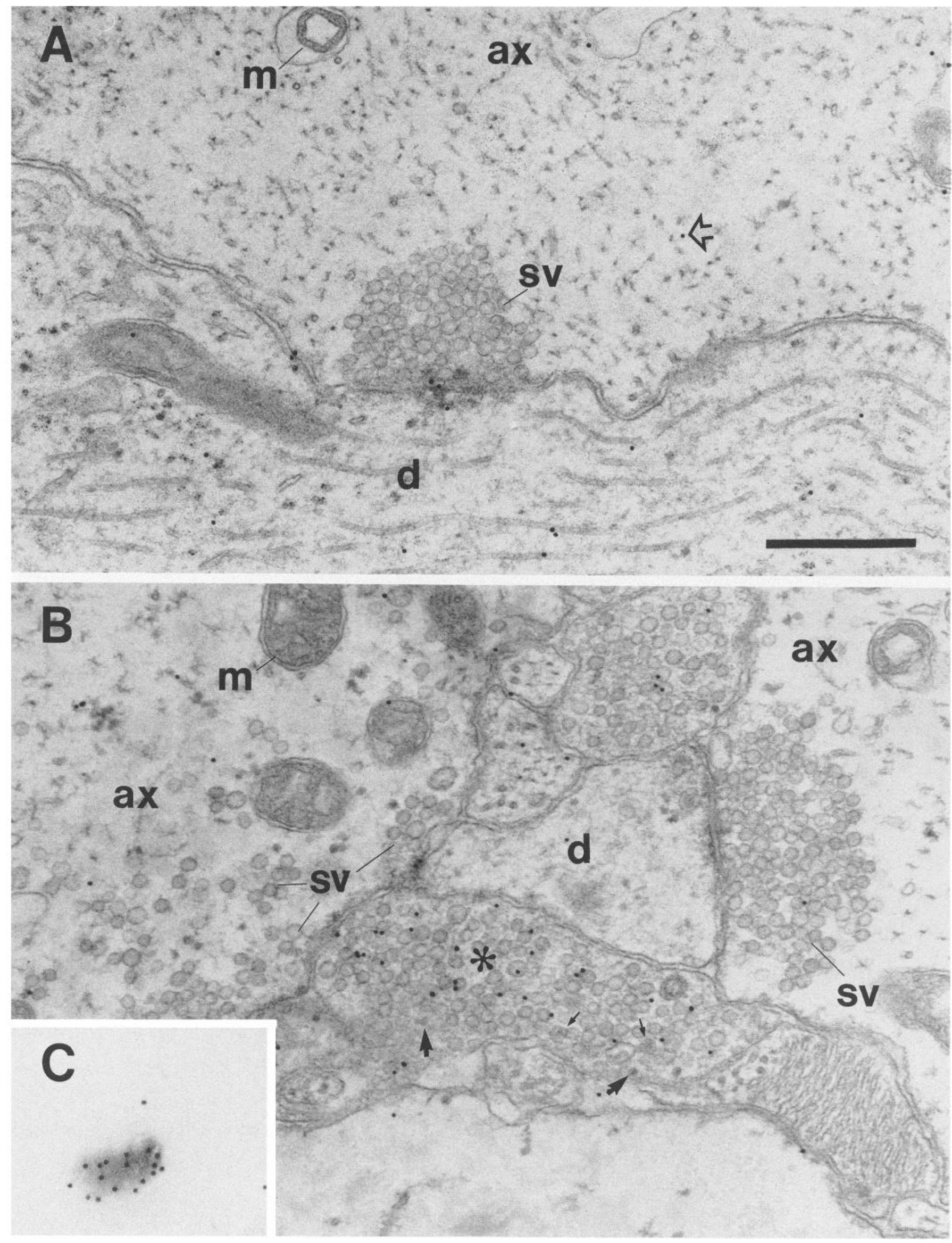
no acids between compartments during the fixation process. If, for instance, the ATP level drops rapidly in synaptic regions following exposure to the fixative, a leakage of glutamate could occur from synaptic vesicles (see Burger et al., 1989) to the surrounding axon matrix, before the amino acids have become irreversibly fixed. If so, one would expect a zone of elevated glutamate immunoreactivity surrounding the vesicle clusters. However, the gold-particle density in the matrix area adjacent to synaptic vesicle clusters did not differ significantly from that in more distant axon matrix areas (see Table 1). We also find it unlikely that a fixation artifact would underlie the different levels of glutamate labeling in dorsal column and giant reticulospinal axon matrix. Both types of axon lie at a similar distance from the spinal cord surface (see Fig. 2), and would be expected to be similarly affected by the fixative. Moreover, preliminary observations of axons in the lateral fiber tract (O. Shupliakov, L. Brodin, S. Cullheim, O. P. Ottersen, and J. Storm-Mathisen, unpublished observations) have shown that there is not always a correlation between the axonal diameter and the intensity of glutamate labeling, further supporting that the differential labeling of axoplasmic matrix in dorsal column and reticulospinal axons is not simply a size-related fixation artifact.

\section{Glutamate accumulation in synaptic vesicles of lampreys and other vertebrates}

The density of gold particles over densely packed synaptic vesicle clusters was found to correspond to that of osmium-treated glutamate conjugates with about $30 \mathrm{mM}$ fixed glutamate. A subtraction of the axon matrix within the cluster gives about twice this value, and if the thickness of the vesicle membrane is taken into account, an even higher value is reached. Furthermore, the comparison with test conjugates may lead to an under- rather than an overestimation of the glutamate concentration in synaptic vesicles. Whereas the glutamate in a test conjugate is evenly distributed, a section of a synaptic vesicle cluster can be expected to contain local concentration peaks over intravesicular regions, which may result in a steric hindrance of antibody binding (see also Ottersen, 1989). Thus, while we estimate the intravesicular concentration of fixed glutamate to be at least $60 \mathrm{mM}$, this value must be regarded as approximate. It should also be recalled that the concentration of fixed amino acid amenable to immunocytochemical study is lower than the concentration of free amino acid in vivo, as a proportion of the amino acids will inevitably be lost during fixation. The proportion that is lost amounts to about $15-20 \%$ in mammalian brain under optimal fixation by perfusion and is similar or higher in immersion-fixed tissue (Storm-Mathisen and Ottersen, 1990). This notwithstanding, an intravesicular concentration of free glutamate similar to that presently estimated for fixed glutamate was estimated biochemically in a recent study of synaptic vesicles immuno-isolated from rat brain (Burger et al., 1989).

The glutamate transporter in synaptic vesicles of lampreys has not been characterized, but recent comparative studies of vertebrates ranging from elasmobranch fish to mammals (Tabb and Ueda, 1991) suggest that the properties of the glutamate transporter are similar among vertebrates. These include a dependence on ATP and chloride ions, and a strict selectivity for L-glutamate versus L- and D-aspartate (see also Naito and Ueda, 1985; Maycox et al., 1988). Whereas the affinity for L-glutamate was always found to be in the millimolar range, some species variations were noted.

When comparing the present data in lamprey with immunogold studics in mammals (Ottersen ct al., 1990; Storm-Mathisen and Ottersen, 1990; Ji et al., 1991; cf. also Watson, 1988), the ratio between the glutamate level in clusters of synaptic vesicles and axoplasm appears very large, in particular for the giant reticulospinal axons. The difference may partly be due to the favorable structure of lamprey synapses, with dense vesicle clusters surrounded by large areas of axoplasmic matrix. It is possible, however, that the high glutamate level in reticulospinal vesicle clusters, despite an estimated extravesicular concentration of only about $0.4 \mathrm{mM}$ (see Table 1, Fig. 5), reflects a comparatively high affinity of the glutamate transporter in lamprey (cf. Tabb and Ueda, 1991).

\section{Further evidence that glutamate is released from synaptic vesicles}

While the present data imply that glutamate is stored in synaptic vesicles of giant reticulospinal synapses, a number of studics have provided additional morphological and physiological data on this system, making it an attractive model of a central glutamate synapse. ${ }^{3} \mathrm{H}-\mathrm{D}$-aspartate, a substrate of the plasma membrane EAA transporter, is taken up and transported in individual reticulospinal axons (Brodin et al., 1989), and a blockade of the EAA uptake causes an increase in the overflow of glutamate in the spinal cord (Brodin et al., 1988c). Single reticulospinal EPSPs are depressed by NMDA and kainate/AMPA receptor blockers (see introductory remarks; Brodin et al., 1988b), and the kainate/AMPA receptor-mediated component shows amplitude fluctuations compatible with a probabilistic quantal release (L. Brodin, R. Hill, O. Shupliakov, and S. Redman, unpublished observations). Previous ultrastructural studies have shown that a prolonged stimulation of this synapse causes a marked reduction of the number of synaptic vesicles (Wickelgren et al., 1985), as well as an increase in the number of putative vesicle attachment sites in the synaptic membrane (Pfenninger and Rovainen, 1974; cf. also Thomas and Betz, 1990). Thus, when combined, these studies of the giant reticulospinal synapse strongly support the view that glutamate is released in a quantal fashion from synaptic vesicles. A simultaneous nonquantal, nonvesicular glutamate release (Antonov and Magazanik, 1988) cannot be excluded, although it would appear to be of little importance in the giant reticulospinal synapse, due to the low glutamate concentration in the axoplasmic matrix.

\section{Role of aspartate and homocysteate in synaptic excitation in lamprey}

Aspartate and homocysteate have both been implicated as EAA transmitter candidates (see, e.g., Zeise et al., 1988; Dunlop et al., 1989; Cuénod et al., 1990; Vollenweider et al., 1990; Tracey et al., 1991), but as yet an accumulation of these amino acids

Figure 8. Electron micrographs of reticulospinal $(A)$ and dorsal column $(B)$ synapses stained with GABA antiserum. $B$ includes two synapses (left and right) of large axons considered as excitatory (for criteria, see Results), and one small terminal (asterisk) with electron-dense granules (large arrows) and dense-core vesicles (small arrows). Only the latter axon shows an accumulation of GABA labeling. Abbreviations are as in Figure 3. Scale bar: $0.5 \mu \mathrm{m}$ for $A$ and $B ; 0.65 \mu \mathrm{m}$ for $C$. 

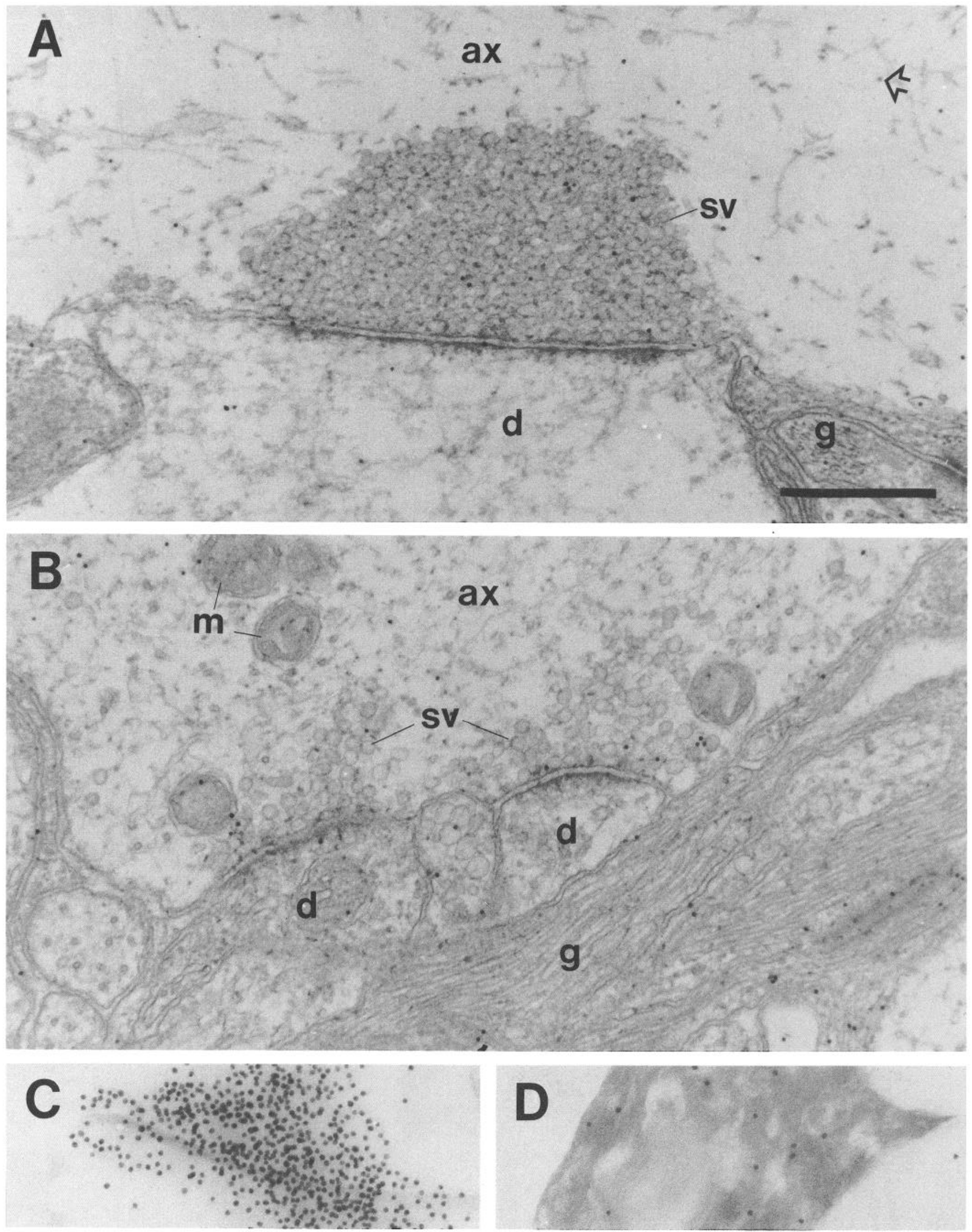

Figure 9. Electron micrographs showing reticulospinal $(A)$ and dorsal column $(B)$ synapses labeled with homocysteate antiserum. $C$ and $D$ show L-glutamate- $(C)$ and L-homocysteate- $(D)$ containing conjugates from the test section incubated along with the tissue section. Note that the slight accumulation of gold particles over synaptic vesicle areas is accompanied by some labeling of the glutamate-containing conjugate in the test section. Abbreviations and open arrow are as in Figure 3. Scale bar: $0.5 \mu \mathrm{m}$ for $A$ and $B ; 0.65 \mu \mathrm{m}$ for $C$ and $D$. 
in synaptic vesicles has not been demonstrated (Naito and Ueda, 1985; Maycox et al., 1988; Nicholls, 1989; McMahon and Nicholls, 1990; Villanueva et al., 1990; cf., however, Dunlop et al., 1991).

In the present study, aspartate immunoreactivity was observed in neuronal cell bodies, and previous microdialysis studies have shown that the resting extracellular level of aspartate is comparable to that of glutamate (Brodin et al., 1988c). However, both of the excitatory synapses studied here appeared virtually devoid of aspartate, which argues against a role in synaptic transmission. We do not rule out the possibility that aspartate acts as a transmitter in other spinal cord synapses in lamprey (cf. Tracey et al., 1991), since a complete survey of aspartate immunoreactivity has not yet been performed. A very low level of aspartate immunoreactivity in terminals of excitatory synapses has been reported in several mammalian fiber systems (Maxwell et al., 1990; Zhang et al., 1990; Ji et al., 1991)

The level of homocysteate-like immunoreactivity was low in all areas examined, although a faint aggregation of labeling occurred over synaptic vesicle clusters in dorsal column and giant reticulospinal axons. However, the homocysteate antiserum cross-reacted weakly with the coprocessed glutamate conjugate included in the test sandwich (cf. also homocysteine sulfinic acid; Zhang and Ottersen, 1992), and hence our interpretation is in line with previous studies where no significant accumulation of homocysteate-like immunoreactivity could be detected in nerve terminals (Cuénod et al., 1990; Zhang and Ottersen, 1992). However, since the conjugate contains very high levels of glutamate $(150 \mathrm{mM})$, it is difficult to compare the level of immunolabeling of the conjugate directly with that in synaptic vesicles areas, and hence we cannot entirely exclude the possibility that a small amount of homocysteate or a closely similar compound is accumulated in synaptic vesicle clusters (cf. Dunlop et al., 1989).

\section{Possible physiological correlates of the observed differences between giant reticulospinal and dorsal column synapses}

Synaptic mitochondria are likely to be of importance both for the transmitter synthesis and for the supply of energy to the release and uptake machinery (Fonnum, 1984; Nicholls, 1989). Studies in insects and crustaceans (for review, see Atwood and Wojtowicz, 1986) have shown that the number and size of synaptic mitochondria are correlated both with the firing pattern of the presynaptic neuron, and with the properties of individual synapses, such that tonically active synapses contain a large amount of mitochondrial material while phasically active synapses contain lower amounts (see also Kalil et al., 1986; Lnenicka et al., 1986). In our lamprey material, the size of synaptic mitochondria appeared to be similar in dorsal column and giant reticulospinal synapses, while the latter were found to contain much fewer mitochondria, most likely reflecting the differences in activity pattern of the two types of neuron (see introductory remarks). Hence, the dorsal column synapses would, as a group, be expected to be more resistant to fatigue and depletion of vesicles compared to the giant reticulospinal axons (see above; Wickelgren et al., 1985). It must be noted, however, that the properties of different synapses of the same axon may differ within a relatively large range (Koerber and Mendell, 1991; L. Brodin, O. Shupliakov, J. Hellgren, and V. Pieribone, unpublished observations).

In the active glutamatergic synapse, the recycling synaptic vesicles must be continuously refilled with glutamate from the surrounding axoplasm. This glutamate can either have been taken up by the plasma membrane transporter, or synthesized within the neuron, presumably in synaptic mitochondria (Fonnum, 1984; Nicholls, 1989). In a tonically active synapse with frequent vesicle recycling, the refilling of synaptic vesicles would be expected to occur at a high rate. The refilling would be most efficient if the juxtavesicular glutamate level was maintained in the upper part of the affinity range of the glutamate transporter. We therefore propose that the extravesicular glutamate concentration in dorsal column axons is maintained at a relatively high level in order to ensure an efficient supply of releasable glutamate. In contrast, a lower glutamate concentration would seem sufficient in the giant reticulospinal synapse, in which the refilling of vesicles may occur at a lower rate. We do not, however, propose that the axoplasmic glutamate level in itself detcrmincs the release characteristics. Most likely these depend on other factors, including the composition of synapse-associated proteins (for reviews, see Südhoff and Jahn, 1991; Trimble et al., 1991).

\section{References}

Antonov SM, Magazanik MG (1988) Intense non-quantal release of glutamate in an insect neuromuscular junction. Neurosci Lett 93:204 208.

Atwood HL, Wojtowicz JM (1986) Short-term and long-term plasticity and physiological differentiation of crustacean motor synapses. In: International review of neurobiology, Vol 28 (Smythies JR, Bradley RJ, eds), pp 275-362. New York: Academic.

Blackstad TW, Karagülle T, Ottersen OP (1990) MORFOREL, a computer program for two-dimensional analysis of micrographs of biological specimens, with emphasis on immunogold preparations. Comput Biol Med 20:15-34.

Brodin L, Grillner S (1990) The lamprey CNS-an experimentally amenable model for studies of synaptic interactions and integrative functions. In: In vitro preparations from vertebrate central nervous system (Jansen H, ed), pp 103-153. New York: Wiley.

Brodin L, Christenson J, Grillner S (1987) Single sensory neurons activate excitatory amino acid receptors in the lamprey spinal cord. Neurosci Lett 75:75-79.

Brodin L, Buchanan JT, Hökfelt T, Grillner S, Rehfeld JF, Frey P, Verhofstad AAJ, Dockray GJ, Walsh JH (1988a) Immunohistochemical studies of cholecystokinin (CCK)-like peptides and their relation to 5-HT; CGRP and bombesin immunoreactivities in the brainstem and spinal cord of lampreys. J Comp Neurol 271:1-18.

Brodin L, Grillner S, Dubuc R, Ohta Y, Kasicki S, Hökfelt T (1988b) Reticulospinal neurons in lamprey: transmitters, synaptic interactions and their role during locomotion. Arch Ital Biol 126:317-345.

Brodin L, Tossman U, Ungerstedt U, Grillner S (1988c) The effect of an uptake inhibitor (dihydrokainate) on endogenous excitatory amino acids in the lamprey spinal cord as revealed by microdialysis. Brain Res 458:166-169.

Brodin L, Ohta Y, Hökfelt T, Grillner S (1989) Further evidence for excitatory amino acid transmission in lamprey reticulospinal neurons: retrograde labeling with $\left({ }^{3} \mathrm{H}\right) \mathrm{D}$-aspartate. J Comp Neurol 281:225233.

Brodin L, Shupliakov O, Ottersen OP, Storm-Mathisen J (1991) Synaptic regions of reticulospinal axons contain high levels of glutamate. Acta Physiol Scand 143:52.

Broman J, Ottersen OP (1992) Cervicothalamic tract terminals are enriched in glutamate-like immunoreactivity: an electron microscopic doublc-labcling study in the cat. J Ncurosci 12:204-221.

Buchanan JT, Brodin L, Dale N, Grillner S (1987) Reticulospinal neurones activate excitatory amino acid receptors. Brain Res 408 : 321-325.

Burger PM, Mehl E, Cameron PL, Maycox P, Baumert M, Lottspeich F, De Camilli P, Jahn R (1989) Synaptic vesicles immunoisolated from rat cerebral cortex contain high levels of glutamate. Neuron 3: 715-720.

Christenson J, Grillner S (1992a) Primary afferents evoke excitatory amino acid receptor-mediated EPSPs that are modulated by presynaptic $\mathrm{GABA}_{\mathrm{B}}$ receptors in lamprey. $\mathrm{J}$ Neurophysiol, in press. 
Christenson J, Bohman A, Lagerbäck PA, Grillner S (1987a) The dorsal cell, one class of primary sensory neurone in the lamprey spinal cord. I. Touch, pressure, but no nociception-a physiological study. Brain Res 440:1-8.

Christenson J, Bohman A, Lagerbäck P $\AA$, Grillner S (1987b) The dorsal cell, one class of primary sensory neurone in the lamprey spinal cord. II. A light and electron-microscopical study. Brain Res 440:917.

Cuénod M, Do KQ, Grandes P, Morino P, Streit P (1990) Localization and release of homocysteic acid, an excitatory sulfur-containing amino acid. J Histochem Cytochem 38:1713-1715.

Dunlop J, Mason H, Grieve A, Griffiths R (1989) Excitatory sulphur amino acid-evoked neurotransmitter release from rat brain synaptosome fractions. J Neural Transm 78:195-208.

Dunlop J, Fear A, Griffiths R (1991) Glutamate uptake into synaptic vesicles: inhibition by sulphur amino acids. Neuro Report 2:377-379.

Fonnum F (1984) Glutamate: a neurotransmitter in mammalian brain. J Neurochem 42:1-11.

Grillner S, Wallén P, Brodin L, Lansner A (1991) Neuronal network generating locomotor behavior in lamprey: circuitry, transmitters, membrane properties, and simulation. Annu Rev Neurosci 14:169199.

Hepler JR, Toomim CS, McCarthy KD, Conti F, Battaglia G, Rustioni A, Petrusz P (1988) Characterization of antisera to glutamate and aspartate. J Histochem Cytochem 36:13-22.

Hollman M, O'Shea-Greenfield A, Rogers SW, Heinemann S (1989) Cloning by functional expression of a functional glutamate receptor. Nature 342:643-648.

Ji Z, Aas JE, Laake J, Walberg F, Ottersen OP (1991) An electron microscopic, immunogold analysis of glutamate and glutamine in terminals of rat spinocerebellar fibers. J Comp Neurol 307:296-310.

Kalil RE, Dubin MW, Scott G, Stark LA (1986) Elimination of action potentials blocks the structural development of retinogeniculate synapses. Nature 323:156-158.

Kasicki S, Grillner S, Ohta Y, Dubuc R, Brodin L (1989) Phasic modulation of reticulospinal neurones during fictive locomotion and other types of spinal motor activity in lamprey. Brain Res 484:203216.

Koerber HR, Mendell LM (1991) Modulation of synaptic transmission at Ia-afferent fiber connections on motoneurons during high-frequency stimulation: role of postsynaptic target. J Neurophysiol 65:590597.

Laake JH, Gundersen V, Nordbo G, Ottersen OP, Storm-Mathisen J (1986) An antiserum against glutamine. In: Excitatory amino acids (Roberts PJ, Storm-Mathisen J, and Bradford HF, eds), pp 448-450. London: Macmillan.

Liu C-J, Grandes P, Matute C, Cuenod M, Streit P (1989) Glutamatelike immunoreactivity revealed in rat olfactory bulb, hippocampus and cerebellum by monoclonal antibody and sensitive staining method. Histochemistry $90: 427-445$.

Lnenicka GA, Atwood HL, Marin L (1986) Morphological transformation of synaptic terminals of a phasic motoneuron by long-term tonic stimulation. J Neurosci 6:2252-2258.

Masu M, Tanabe Y, Tsuchida K, Shigemoto R, Nakanishi S (1991) Sequence and expression of a metabotropic glutamate receptor. $\mathrm{Na}$ ture 349:760-765.

Maxwell DJ, Christie VM, Short AD, Storm-Mathisen J, Ottersen OP (1990) Central boutons of glomeruli are enriched with L-glutamatelike immunoreactivity in the spinal cord of the cat. Neuroscience 36: 83-104.

Maycox P, Deckwerth T, Hell, J, Jahn R (1988) Glutamate uptake by brain synaptic vesicles. Energy dependence of transport and functional reconstitution in proteoliposomes. J Biol Chem 263:15423-15428.

McMahon HT, Nicholls DG (1990) Glutamine and aspartate loading of synaptosomes: a reevaluation of effects on calcium-dependent excitatory amino acid release. J Neurochem 54:373-380.

Monaghan DT, Bridges RJ, Cotman CW (1989) The excitatory amino acid receptors: their classes, pharmacology, and distinct properties in the function of the central nervous system. Annu Rev Pharmacol Toxicol 29:365-402.

Montero VM, Wenthold RJ (1989) Quantitative immunogold analysis reveals high glutamate levels in retinal and cortical synaptic terminals in the lateral geniculate nucleus of the macaque. Neuroscience 31: 639-647.

Moriyoshi K, Masu M, Ishii T, Shigemoto R, Mizuno N, Nakanishi S
(1991) Molecular cloning and characterization of the rat NMDA receptor. Nature 354:31-37.

Naito S, Ueda T (1985) Characterization of glutamate uptake into synaptic vesicles. J Neurochem 44:99-109.

Nicholls DG (1989) The release of amino acid neurotransmitters from isolated nerve terminals. J Neurochem 52:331-341.

Ottersen OP ( (1987) Postembedding light- and electron-microscopic immunocytochemistry of amino acids: description of a new model system allowing identical conditions for specificity testing and tissue processing. Exp Brain Res 69:167-174.

Ottersen OP (1989) Postembedding immunogold labeling of fixed glutamate: an electron microscopic analysis of the relationship between gold particle density and antigen concentration. J Chem Neuroanat $2: 57-67$.

Ottersen OP, Storm-Mathisen J (1985) Different neuronal localization of aspartate-like and glutamate-like immunoreactivities in the hippocampus of rat, guinea pig and Senegalese baboon (Papio papio) with a note on the distribution of GABA. Neuroscience 16:589-606.

Ottersen OP, Storm-Mathisen J, Bramham C, Torp R, Laake J, Gundersen V (1990) A quantitative immunocytochemical study of the distribution and synaptic handling of glutamate in rat hippocampus. Prog Brain Res 83:99-140.

Ottersen OP, Zhang N, Walberg F (1992) Metabolic compartmentation of glutamate and glutamine: morphological evidence obtained by quantitative immunocytochemistry in rat cerebellum. Neuroscience 46:519-534.

Pfenninger KH, Rovainen CM (1974) Stimulation and calcium-dependence of vesicle attachment sites in the presynaptic membrane; a freeze-cleave study in the lamprey spinal cord. Brain Res 72:1-23.

Rovainen CM (1974) Synaptic interactions of reticulospinal neurons and nerve cells in the sea lamprey. J Comp Neurol 154:207-233.

Rovainen CM (1979) Neurobiology of lampreys. Physiol Rev 59: 1007-1077.

Smith DS, Järlfors U, Beranek R (1968) The organization of synaptic axoplasm in the lamprey central nervous system. J Cell Biol 46:199_ 219.

Somogyi P, Hodgson J (1985) Antiserum to gamma-aminobutyric acid. III. Demonstration of GABA in Golgi-impregnated neurons and in conventional electron microscopic sections of cat striate cortex. J Histochem Cytochem 33:249-257.

Somogyi P, Halasy K, Somogyi J, Storm-Mathisen J, Ottersen OP (1986) Quantification of immunogold labelling reveals enrichment of glutamate in mossy and parallel fiber terminals in cat cerebellum. Neuroscience 19:1045-1050.

Storm-Mathisen J, Ottersen OP (1990) Immunocytochemistry of glutamate at the synaptic level. J Histochem Cytochem 38:1733-1743.

Storm-Mathisen J, Leknes AK, Bore AT, Vaaland JL, Edminson P, Haug FM-S, Ottersen OP (1983) First visualization of glutamate and GABA in neurones by immunocytochemistry. Nature 301:517520.

Südhof TC, Jahn R (1991) Proteins of synaptic vesicles involved in exocytosis and membrane recycling. Neuron 6:665-677.

Tabb JS, Ueda T (1991) Phylogenetic studies of the synaptic vesicle glutamate transport system. I Neurosci 11:1822-1828.

Thomas L, Betz H (1990) Synaptophysin binds to physophyllin, a putative synaptic plasma membrane protein. J Cell Biol 111:20412052.

Tracey DJ, DeBiasi S, Phend K, Rustioni A (1991) Aspartate-like immunoreactivity in primary afferent neurons. Neuroscience 40:673686.

Trimble WS, Linial M, Scheller RH (1991) Cellular and molecular biology of the presynaptic nerve terminal. Annu Rev Neurosci 14: 93-122.

Viana di Prisco G, Dubuc R, Wallń P, Grillner S (1991) 5-Hydroxytryptamine modulates spike frequency regulation in reticulospinal neurons involved in the control of locomotion in lamprey. Neurosci Lett 134:279-283.

Villamera S, Fiedler J, Orrego F (1990). A study in rat brain of endogenous ligands for $N$-methyl-D-aspartate receptors. Neuroscience $37: 23-90$

Vollenweider FX, Cućnod M, Do KQ (1990) Effcct of climbing fiber deprivation on release of endogenous aspartate, glutamate and homocysteate in slices of rat cerebellar hemispheres and vermis. J Neurochem 54:1533-1540.

Watson AHD (1988) Antibodies to GABA and glutamate label neu- 
rons with morphologically distinct synaptic vesicles in the locust central nervous system. Neuroscience 26:33-44.

Wickelgren WO, Leonard JP, Grimes MJ, Clark RD (1985) Ultrastructural correlates of transmitter release in presynaptic areas of lamprey reticulospinal axons. J Neurosci 5:1188-1201.

Zeise ML, Knöpfel T, Cuénod M, Zieglgänsberget W (1988) L-Homocysteic acid as an endogenous $N$-methyl-D-aspartate agonist in the rat neocortex. In: Frontiers in excitatory amino acid research (Cavalheiro EA, Lehmann J, Turski L, eds), pp 187-192. New York: Liss. Zhang N, Ottersen OP (1992) Differential distribution of two sulphurcontaining amino acids in rat cerebellum: an immunocytochemical investigation using antisera to taurinc and homocysteic acid. Exp Brain Res, in press.

Zhang N, Walberg F, Laake JH, Meldrum BS, Ottersen OP (1990) Aspartate-like and glutamate-like immunoreactivities in the inferior olive and climbing fiber system: a light microscopic and semiquantitative electron microscopic study in rat and baboon (Papio anubis). Neuroscience 38:61-80.

Zhang N, Laake JH, Nagelhus E, Storm-Mathisen J, Ottersen OP (1991) Distribution of glutamine-like immunoreactivity in the cerebellum of rat and baboon (Papio anubis) with reference to the issue of metabolic compartmentation. Anat Embryol 184:213-223. 